Check for updates

Cite this: J. Mater. Chem. C, 2020, 8, 15368

Received 30th June 2020,

Accepted 3rd September 2020

DOI: 10.1039/d0tc03094e

rsc.li/materials-c

\section{Impact of p-type doping on charge transport in blade-coated small-molecule:polymer blend transistors $\dagger$}

\author{
Aniruddha Basu, (D)*a Muhammad Rizwan Niazi, ${ }^{a}$ Alberto D. Scaccabarozzi, ${ }^{a}$ \\ Hendrik Faber, (D) ${ }^{a}$ Zuping Fei, ${ }^{b}$ Dalaver H Anjum, ${ }^{c}$ Alexandra F. Paterson, ${ }^{a}$ \\ Olga Boltalina, ${ }^{d}$ Martin Heeney (D) ${ }^{\mathrm{e}}$ and Thomas D. Anthopoulos (iD) ${ }^{a}$
}

\begin{abstract}
Blade-coating is a roll-to-roll (R2R) compatible processing technique and has the potential to address the industry's needs for scalable manufacturing of future organic electronics. Here we investigate the applicability of blade-coating for the fabrication of organic thin-film transistors (OTFTs) based on best-in-class organic semiconducting blends comprised of the conjugated small-molecule 2,7-dioctyl[1]benzothieno[3,2-b][1] benzothiophene $\left(\mathrm{C}_{8}\right.$-BTBT), and the conjugated polymer poly(indacenodithiophene-co-benzothiadiazole) $\left(C_{16}\right.$ IDT-BT). We show that the operating characteristics of blade-coated transistors consistently outperform devices prepared via spin-coating, showcasing the compatibility of the technique. Introducing the molecular p-dopant $\mathrm{C}_{60} \mathrm{~F}_{48}$ into the binary $\mathrm{C}_{8}$-BTBT: $\mathrm{C}_{16}$ IDT-BT blend formulation, in combination with carefully optimized blade-coating conditions, helps to enhance the performance of the ensuing transistors further resulting in a maximum hole mobility of $\approx 14 \mathrm{~cm}^{2} \mathrm{~V}^{-1} \mathrm{~s}^{-1}$, and an all-around improvement of the device operating characteristics. Our results show that $p$-doped blend OTFTs can be manufactured using industry relevant processing techniques without sacrificing their state-of-the-art performance.
\end{abstract}

\section{Introduction}

The vast majority of modern day electronics rely on inorganic materials that require complex and costly manufacturing processes. ${ }^{1,2}$ Emerging semiconductor technologies such as organic semiconductors (OSCs) promise to provide an alternative option for implementation in various future optoelectronics including flexible, foldable, wearable, stretchable and even disposable devices for application in health, security, information, display, sensing and energy generation, among many others. ${ }^{3-8}$ This has resulted in continuous exploration of OSCs as active layers in printable organic photovoltaics (OPVs),

\footnotetext{
${ }^{a}$ King Abdullah University of Science and Technology (KAUST), KAUST Solar Center (KSC), Thuwal 23955-6900, Kingdom of Saudi Arabia.

E-mail: thomas.anthopoulos@kaust.edu.sa, aniruddha.basu@kaust.edu.sa

${ }^{b}$ Institute of Molecular Plus, Tianjin Key Laboratory of Molecular Optoelectronic Science, Tianjin University, Tianjin, 300072, P. R. China

${ }^{c}$ KAUST CoreLabs, King Abdullah University of Science and Technology, Thuwal 23955-6900, Kingdom of Saudi Arabia

${ }^{d}$ Department of Chemistry, Colorado State University, Fort Collins, CO 80523, USA ${ }^{e}$ Department of Chemistry and Centre for Plastic Electronics, Imperial College London, South Kensington, London SW7 2AZ, UK

$\dagger$ Electronic supplementary information (ESI) available: Transistor measurements, transistor parameter distribution, atomic force microscopy, GIWAXS analysis. See DOI: 10.1039/d0tc03094e
}

organic light emitting diodes (OLEDs), thermoelectrics, and organic thin-film transistors (OTFTs). ${ }^{3,6,9-12}$

Among the various demonstrated technologies, OTFTs are highly promising as the building blocks for large-area electronics and more broadly for the internet of things (IoT) device ecosystem. ${ }^{13,14}$ During the past three decades, continuous progress on materials development, interfaces and device engineering have resulted in field-effect mobility $(\mu)$, a key figure of merit, of $>20 \mathrm{~cm}^{2} \mathrm{~V}^{-1} \mathrm{~s}^{-1}{ }^{5,15-18}$ Laboratory-based research often relies on the widely available film deposition method of spin-coating. Unfortunately, the latter is wasteful (90-95\% material waste) and incompatible with continuous, high-throughput roll-to-roll (R2R) printing techniques relevant to manufacturing of the envisaged electronics of the future. To this end, meniscus guided R2R compatible techniques such as blade, knife, bar and slot-die coating, are more relevant to the industry offering $95-99 \%$ utilization of the OSC ink..$^{5,9,10,19-23}$ The drying kinetics during solution-phase deposition is known to strongly influence the morphology, crystallinity and microstructure of the resulting layers, ultimately dictating the charge transport properties of the formed OSC films and their devices. ${ }^{5,23-28}$ Though meniscus guided techniques have been used in the past to deposit OSC films with aim to understand the structure-property-performance relationship for OTFTs, ${ }^{27,29-34}$ the majority of these studies relied on low to medium coating speeds. ${ }^{27}$ 
In recent years, molecular doping of OSCs has emerged as promising method to enhance the performance of solutionprocessed OTFTs. ${ }^{18,35-48}$ In this regard, we have recently developed p-doped OTFTs with hole mobility of $13 \mathrm{~cm}^{2} \mathrm{~V}^{-1} \mathrm{~s}^{-1}$ based on spin-coated blend semiconducting channels based on the small-molecule 2,7-dioctyl[1]benzothieno $\quad[3,2-b][1]$ benzothiophene $\left(\mathrm{C}_{8}\right.$-BTBT), and the polymer poly(indacenodithiophene-cobenzothiadiazole) $\left(\mathrm{C}_{16}\right.$ IDT-BT). ${ }^{16}$ Key to our success has been the ink-formulation engineering (solvents, material ratios, etc.), in combination with careful choice of drying kinetics (spin-coating and melt-processing conditions). Using this work as our starting point, we attempt to bridge the existing gap between lab-scale and industry relevant manufacturing of high-performance blend OSCs and their use in OTFTs. We first studied the role of coating method (spin vs. blade coating) on the morphology and charge transport of the blend OSCs and their OTFTs. We find that bladecoated devices consistently outperform their spin-coated counterparts, an observation attributed to the superior morphology of blade-coated layers due to different film formation conditions. By introducing the molecular p-dopant $\mathrm{C}_{60} \mathrm{~F}_{48}$ into the $\mathrm{C}_{8}$-BTBT: $\mathrm{C}_{16}$ IDT-BT blend and blade-coating it at industry relevant speeds of $>1 \mathrm{~m} \mathrm{~min}^{-1}$, we are able to improve the mobility of the OTFTs further reaching a maximum value of $14 \mathrm{~cm}^{2} \mathrm{~V}^{-1} \mathrm{~s}^{-1}$. The work highlights the compatibility of high performance blend OSCs with the industry-relevant blade-coating technique while providing important guideline for the processing of high quality blend OSC and the realization of state-of-the-art OTFTs.

\section{Result and discussion}

The molecular structures and corresponding energy levels of $\mathrm{C}_{8}$-BTBT, $\mathrm{C}_{16}$ IDT-BT and the p-dopant $\left(\mathrm{C}_{60} \mathrm{~F}_{48}\right)$ are shown in
Fig. 1a and b, respectively, while Fig. 1c depicts the bladecoating process. Further details on the blade-coating process and the relevant parameters are given in Fig. S1 in the ESI. $\dagger$ Blade-coating involves two main coating regimes: (1) the evaporation regime, and (2) the Landau-Levich (L-L) regime, which depend primarily on the coating speed. ${ }^{25,49,50}$ For the purpose of this work we optimized and set the coating speed at $50 \mathrm{~mm} \mathrm{~s}^{-1}\left(3 \mathrm{~m} \mathrm{~min}^{-1}\right)$ while maintaining the stage temperature at $70{ }^{\circ} \mathrm{C}$. The latter falls within the $\mathrm{L}-\mathrm{L}$ coating regime $\left(>20 \mathrm{~mm} \mathrm{~s}^{-1}\right)$ and it is representative of industrial roll-to-roll solution printing requirements. ${ }^{23}$ Unlike spin-coating, bladecoating is a meniscus guided coating technique which can help to control the nucleation, crystal growth and orientation of the small molecule (SM) films over a large coating area. ${ }^{51}$ Blade-coating and spin-coating of all blend layers investigated was performed entirely under inert nitrogen atmosphere in order to eliminate extrinsic effects such as unintentional doping, variable humidity conditions etc.

We employed polarized optical microscopy (POM), atomic force microscopy (AFM), cross sectional transmission electron microscopy (TEM), and grazing incidence wide angle scattering (GIWAXS) techniques to assess the morphology, vertical phase separation and microstructure of the thin films coated by two coating methods. POM micrographs of blade and spin-cast pristine blend films (Fig. 2a and b) reveal that blade-cast films are characterized by small nucleation density and larger polycrystalline domains. The differences are attributed to the different crystallization/phase-transformation mechanisms involved in the two coating techniques. ${ }^{23}$

AFM analysis of the layers' surfaces reveal the presence of molecular terraces of $\mathrm{C}_{8}$-BTBT on both spin and blade cast blend films, in agreement with previous reports. ${ }^{16,17}$ The height

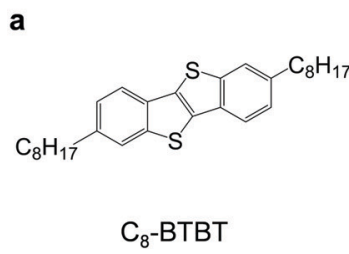

b

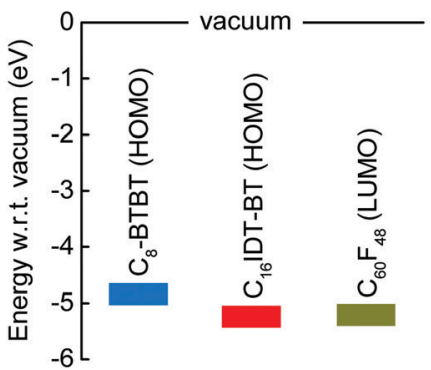

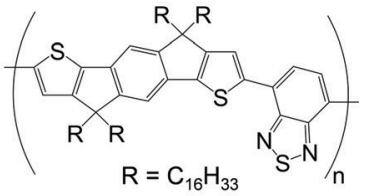

$\mathrm{C}_{16}$ IDT-BT

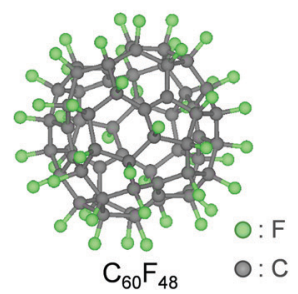

C

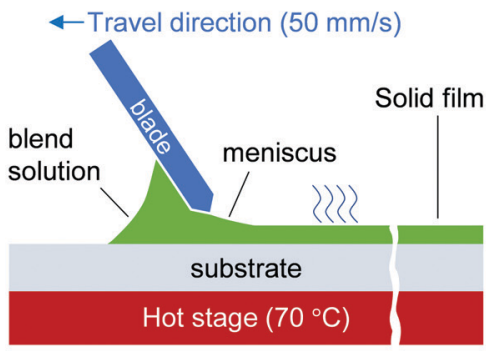

Fig. 1 (a) Chemical structures of $\mathrm{C}_{8}$-BTBT, $\mathrm{C}_{16} I D T-B T$ and $\mathrm{C}_{60} \mathrm{~F}_{48}$ used in this study. (b) Highest occupied molecular orbital (HOMO) energy levels of $\mathrm{C}_{8}$-BTBT and $\mathrm{C}_{16}$ IDT-BT, and lowest unoccupied molecular orbital (LUMO) energy level of $\mathrm{C}_{60} \mathrm{~F}_{48}$. (c) Schematic depicting the blade-coating process and the various parameters used. 

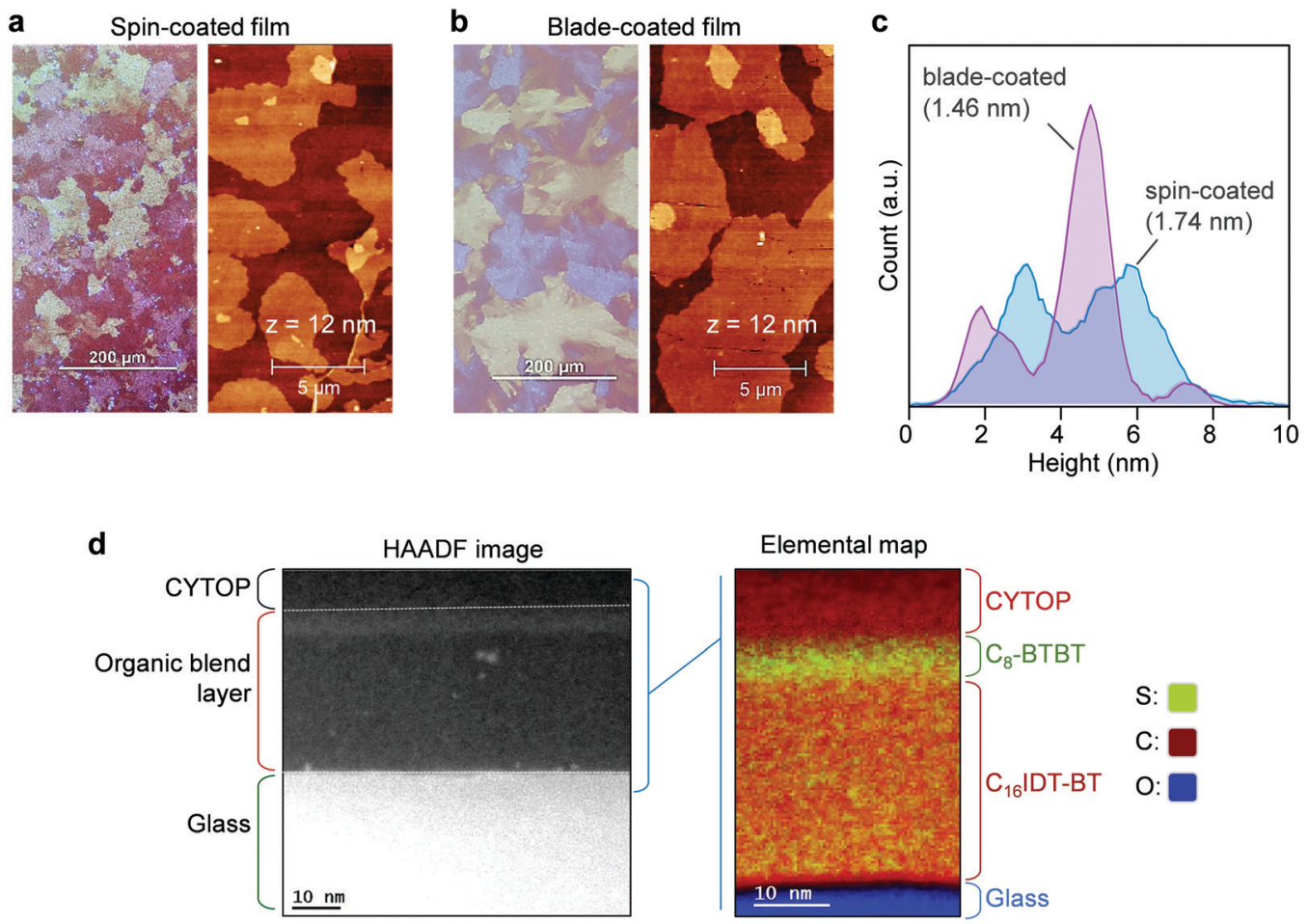

Fig. 2 ( $a$ and b) Polarized optical microscopy and atomic force microscopy images of spin-coated and blade-coated $C_{8}-B$ BTB: $C_{16}$ IDT-BT blend layers. (c) Surface height distribution profiles extracted from the AFM images of the spin-coated and blade-coated blend films. (d) X-TEM analysis of the $\mathrm{C}_{8}$-BTBT: $\mathrm{C}_{16}$ IDT-BT blend film deposited on glass. The image on the left is the HAADF-STEM image while the one on the right shows an RGB Composite of $\mathrm{S}, \mathrm{C}$, and $\mathrm{O}$ maps generated by processing the STEM-EELS data-cubes.

histograms (Fig. 2c) extracted from $20 \times 20 \mu \mathrm{m}^{2}$ AFM scans, reveal that the majority of the molecular plateaus in blade-coated films have a height in the range $4-5.40 \mathrm{~nm}$ (peak at $\approx 4.7 \mathrm{~nm}$ ) and a smaller fraction of plateaus with heights in the range $1.40-2.70 \mathrm{~nm}$ (peak at $\approx 1.9 \mathrm{~nm}$ ). Similarly, the height distribution for the spin-coated films also exhibit two main peaks, one between $2.40-3.64 \mathrm{~nm}$ (peak at $\approx 3.1 \mathrm{~nm}$ ) and a second one between $4.8-6.3 \mathrm{~nm}$ (peak at $\approx 5.75 \mathrm{~nm}$ ). These differences manifest in a lower root mean square (RMS) surface roughness of $1.46 \mathrm{~nm}$ for the blade-coated layers as compared to $1.74 \mathrm{~nm}$ for the spin-coated films. The blade-cast films exhibit larger polycrystalline domains, in line with POM images, suggesting a higher film quality than the spin-cast layers. The characteristic height distributions seen in both films is most likely the result of the presence of domains (crystallites) composed of different number of monomolecular layers of the $\mathrm{C}_{8}$-BTBT lamella, while the broadening of these peaks is most likely the result of the nonuniform nature of the vertical phase-separated system. To this end, a monomolecular terrace step height of $\approx 2.8 \mathrm{~nm}$ should be expected for the $c$-axis of $\mathrm{C}_{8}$-BTBT, which should dominate in films with an out-of-plane molecular packing motif. The measured surface heights are those in broad agreement with the presence of large monomolecular domains.

Lastly, we investigated the vertical phase separation in the blend layers using transmission electron microscopy (TEM) in conjunction electron energy loss spectroscopy (EELS) mode. The vertical phase separation in small-molecule:polymer blend systems is believed to proceed via the nucleation and growth of the small-molecule component. ${ }^{16,17,52}$ In particular, the asdeposited wet layer first undergoes a liquid-liquid phase separation (driven by the surface energies of the different blend components) before the small-molecule (i.e. $\mathrm{C}_{8}$-BTBT here) starts to crystallize. This crystallization even becomes particularly pronounced at the surface/air interface of the supersaturated solution, leading to the formation of the small-molecule dominated layer surface. The remaining part of the layer eventually dries up to form the polymer-dominated phase at the bottom interface (substrate/film) of the composite film. Indeed, the Sulphur map of the blend films shown in Fig. 2d, confirms the AFM observations that the surface of the blend layer is dominated by the presence of $\mathrm{C}_{8}$-BTBT molecules that form a stratified layer approximately $\approx 7 \mathrm{~nm}$ in thickness.

To understand the impact of morphology on charge transport properties, we have fabricated top-gate bottom-contact (TG-BC) OTFTs based on spin-coated blade-coated channel layers of undoped $\mathrm{C}_{8}$-BTBT: $\mathrm{C}_{16}$ IDT-BT blends using identical ink-formulation protocols to those reported previously. ${ }^{16,17,53}$ The ensuing devices were electrically characterized under nitrogen atmosphere at room temperature in order to avoid extrinsic effects such as unintentional doping or degradation due to the presence of oxygen, or other atmospheric oxidants etc. The representative transfer and output curves, measured in linear and saturation biasing regimes, are shown in Fig. 3a and Fig. S2 $(\mathrm{ESI} \dagger)$. The average saturation mobility $\left(\mu_{\mathrm{SAT}}\right)$ for spin-cast 

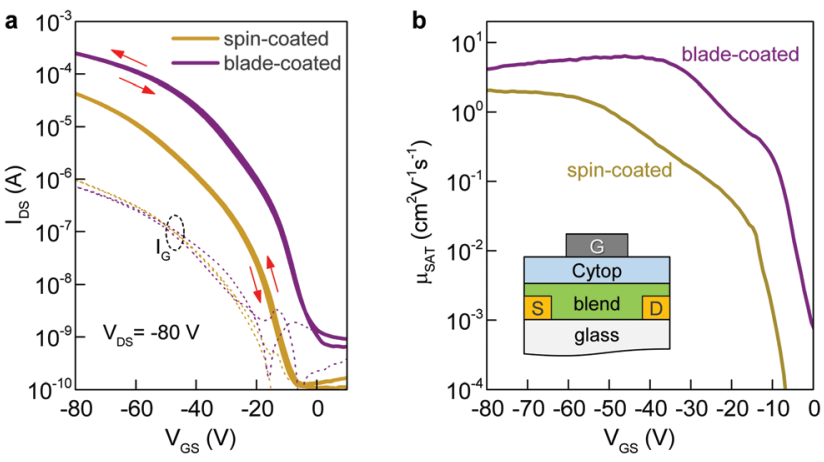

Fig. 3 (a) Transfer characteristics of spin-coated and blade-coated $\mathrm{C}_{8}$-BTBT: $\mathrm{C}_{16}$ IDT-BT OTFTs measured at $V_{\mathrm{DS}}=-80 \mathrm{~V}$. Dotted lines represents the corresponding gate leakage $\left(I_{\mathrm{G}}\right)$ currents. The channel width and length of the devices were $1000 \mu \mathrm{m}$ and $80 \mu \mathrm{m}$, respectively. (b) Hole mobility measured in saturation ( $\mu_{\mathrm{SAT}}$ ) versus applied gate bias $\left(V_{G S}\right)$ for the $C_{8}$-BTBT: $C_{16}$ IDT-BT-based OTFTs shown in (a).

devices was found to be $2.4( \pm 0.7) \mathrm{cm}^{2} \mathrm{~V}^{-1} \mathrm{~s}^{-1}$, in excellent agreement to our earlier published reports. ${ }^{16,17}$ Details of the method used to calculate $\mu_{\mathrm{SAT}}$ are provided in the Experimental section of the manuscript. On the other hand, TGBC devices based on blade-cast films yielded a significantly higher $\mu_{\mathrm{SAT}}$ value of $6 \mathrm{~cm}^{2} \mathrm{~V}^{-1} \mathrm{~s}^{-1}$. Fig. S3 (ESI $\dagger$ ) shows the statistical comparison of the device performance of spin-coated and blade-coated OTFTs. The measured current-voltage $(I-V)$ characteristics are hysteresis free which is indicative of a high quality semiconductor/dielectric interface.

We also assessed the reliability of the calculated $\mu_{\mathrm{SAT}}$ values by examining the mobility dependence on $V_{\mathrm{GS}}$ (Fig. $\left.3 \mathrm{~b}\right)$ at $V_{\mathrm{DS}}=$ $-80 \mathrm{~V}$ for both spin- and blade-coated devices. OTFTs prepared via spin-coating exhibit a plateau in $\mu_{\mathrm{SAT}}$ at high $V_{\mathrm{GS}}$ range while for blade-coated transistors the mobility peaks $\left(6.4 \mathrm{~cm}^{2} \mathrm{~V}^{-1} \mathrm{~s}^{-1}\right)$ at lower $V_{\mathrm{GS}}$ followed by a reduction $\left(4.1 \mathrm{~cm}^{2} \mathrm{~V}^{-1} \mathrm{~s}^{-1}\right)$ at higher voltages. This is a known phenomenon in OTFTs and has been previously associated with the presence of contact resistance that is also affected by the applied gate-field. ${ }^{54}$ To avoid overestimation, we thus use the mobility values calculated at $V_{\mathrm{GS}}=-80 \mathrm{~V}$ as the representative parameter for both spin-cast and blade-coated transistors. The improved $\mu_{\mathrm{SAT}}$ for bladecoated devices manifests as larger channel on-currents (a factor of six) and lowered $V_{\mathrm{TH}}$ as compared to spin-coated transistors (Table S1, ESI $\dagger$ ). The noticeable differences in the charge transport between spin-coated and blade-coated OTFTs are almost certainly attributed to morphology and microstructure differences of the channel layer. ${ }^{55-57}$ Importantly, both types of OTFTs show good shelf lifetime with their initial operating parameters being retained for up to six months of storage in a nitrogen atmosphere.

\subsection{Effect of molecular p-type doping}

We have previously shown that addition of $\mathrm{C}_{60} \mathrm{~F}_{48}$ in spincoated $\mathrm{C}_{8}$-BTBT: $\mathrm{C}_{16}$ IDT-BT blend channels increases the hole mobility of the OTFTs to $13 \mathrm{~cm}^{2} \mathrm{~V}^{-1} \mathrm{~s}^{-1} \cdot{ }^{16}$ Motivated by this early work, we deposited pristine and $\mathrm{C}_{60} \mathrm{~F}_{48}$-doped $\mathrm{C}_{8}$-BTBT: $\mathrm{C}_{16}$ IDT-BT layers via blade-coating. Kelvin probe (KP) measurements performed on both types of blend layers (Fig. S4, $\mathrm{ESI} \dagger$ ) reveal a significant shift in work function (WF) from $4.8 \mathrm{eV}$, for the pristine blend, to $5.3 \mathrm{eV}$ upon addition of $4.5 \mathrm{~mol} \% \mathrm{C}_{60} \mathrm{~F}_{48}$. These results provide direct evidence of successful p-doping of the $\mathrm{C}_{8}$-BTBT: $\mathrm{C}_{16}$ IDT-BT blend by $\mathrm{C}_{60} \mathrm{~F}_{48}$.

Next we studied the morphology and microstructure of the blade-coated layers using POM, AFM and GIWAXS. The POM and AFM images shown in Fig. $4 \mathrm{a}$ and $\mathrm{b}$ reveal the presence of large crystalline domains and molecular terraces due to the vertical phase separation of $\mathrm{C}_{8}$-BTBT at the surface of the blend
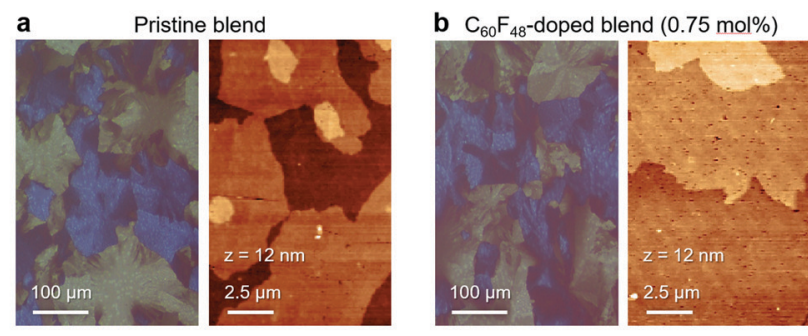

d

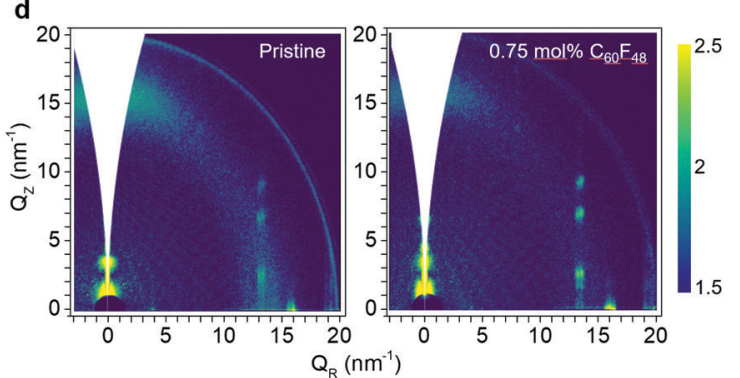

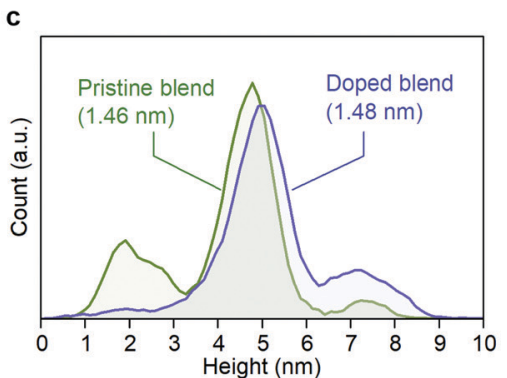

e

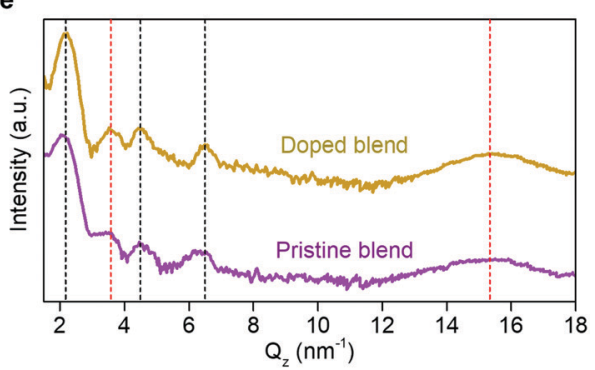

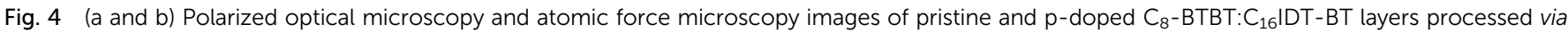

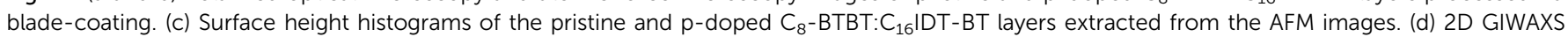
images of the pristine and $p$-doped blend layers. (e) Plots of the integrated intensity versus $Q$ ( $\mathrm{nm}^{-1}$ ) for out-of-plane Bragg sheets taken from (d). 
film. $\mathrm{C}_{60} \mathrm{~F}_{48}$-doped film exhibit larger $\mathrm{C}_{8}$-BTBT crystalline domains/terraces than the pristine layer. The height distribution profile shown in Fig. 4c supports this conclusion since the surface exhibits a single dominant peak at $\approx 5.5 \mathrm{~nm}$, which equates to approximately two monomolecular layers of $\mathrm{C}_{8}$-BTBT. The pristine layer on the other hand shows a bimodal distribution of terrace heights, one at $1.9 \mathrm{~nm}$ (single monomolecular terrace) and a stronger one at $4.8 \mathrm{~nm}$ (double monomolecular terrace), supporting the existence of smaller area terraces/ crystals with different heights. As a result of these features the RMS surface roughness of pristine and $\mathrm{C}_{60} \mathrm{~F}_{48}$-doped blend layers are similar and equal to 1.46 and $1.48 \mathrm{~nm}$, respectively. Fig. S5a (ESI $\dagger$ ) shows the AFM images of the blend films doped with several different $\mathrm{C}_{60} \mathrm{~F}_{48}$ concentrations (i.e. $0.1 \%, 2 \%$ and $4.25 \%$ ), while Fig. S5b-d (ESI $\dagger$ ) show the evolution of the surface height distribution and surface roughness RMS for blend layers with different dopant concentrations, respectively. AFM images with $20 \times 20 \mu^{2}$ scan area were used to extract the height distribution and RMS roughness data. Evidently, the presence of $\mathrm{C}_{60} \mathrm{~F}_{48}$, at optimal dopant concentration, enables the formation of blend films with more uniform molecular traces (more compact films) and lower RMS surface roughness.

Further insights into the microstructure of the blend layers and the role of $\mathrm{C}_{60} \mathrm{~F}_{48}$ were obtained via two-dimensional GIWAXS (2D GIWAXS) measurements. Fig. 4d shows the 2D GIWAXS images taken for a pristine and a $\mathrm{C}_{60} \mathrm{~F}_{48}$-doped (0.75 mol\%) blade-coated $\mathrm{C}_{8}$-BTBT: $\mathrm{C}_{16}$ IDT-BT blend films. The crystal lattice of the doped layer appears similar to that of the pristine, in agreement with previous reports on the effect of doping on spin-coated films. ${ }^{58}$ In particular, the 2D GIWAXS patterns show a diffraction in the out-of-plane direction (Fig. 4e) at $Q_{z}=3.6 \mathrm{~nm}^{-1}$ where the broad feature at $15 \mathrm{~nm}^{-1}$ is associated to $\mathrm{C}_{16} \mathrm{IDT}-\mathrm{BT}$ (red dotted line), while the other highly oriented and sharp diffractions are related to $\mathrm{C}_{8}$-BTBT (black dotted line). The integrated intensity $v s . Q_{z}\left(\mathrm{~nm}^{-1}\right)$ plots for out-of-plane Bragg reflections revealed only minor differences between the doped and pristine blend films, and are most likely attributed to small differences in the films thicknesses. Overall, the small molecule exhibits a high degree of lamellar ordering, as evident by the well resolved $(00 l)$ diffractions, with higher-order peaks $(L=1,2,3)$ in the out-of-plane direction. A similar high intensity of $\mathrm{C}_{8}$-BTBT related diffractions is also observed along the $(11 L)$ diffractions centered at around $13.4 \mathrm{~nm}^{-1}$ (Fig. S6a, ESI $\dagger$ ). Addition of $\mathrm{C}_{60} \mathrm{~F}_{48}$ at two different concentrations of 0.1 and 2 mol\% leads to similar observations i.e. a well resolved progression of higher-order diffraction peaks corresponding to the $(00 l)$ crystal plane (Fig. S6b, ESI $\dagger$ ). Furthermore, the FWHM of the diffraction peak for the doped film appears to be smaller than the pristine film (Fig. S6c, ESI $\dagger$ ). The latter feature indicates improved ordering and the existence of larger $\mathrm{C}_{8}$-BTBT crystallites upon optimal doping, in excellent agreement with the AFM analysis (Fig. 4a and b). Overall, these results suggest that addition of small concentrations of $\mathrm{C}_{60} \mathrm{~F}_{48}$ improves the degree of microstructural order in blade coated layers, even though the small molecule phase (i.e. $\mathrm{C}_{8}$-BTBT) remains highly crystalline in all samples.
Next, we fabricate OTFTs via blade-coating using pristine and p-doped ( 0 to 4.25 mol\% $\mathrm{C}_{60} \mathrm{~F}_{48}$ ) $\mathrm{C}_{8}$-BTBT: $\mathrm{C}_{16}$ IDT-BT blends (Fig. S7, ESI $\dagger$ ). Processing and device characterization was performed in nitrogen atmosphere to minimize unintentional side effects. Fig. 5a and b shows representative sets of the transfer and output curves, respectively, for an optimised p-doped

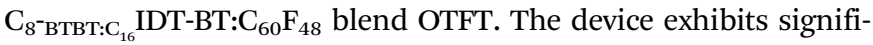
cantly improved performance manifested in higher on-currents and a maximum $\mu_{\mathrm{SAT}}$ value of $14 \mathrm{~cm}^{2} \mathrm{~V}^{-1} \mathrm{~s}^{-1}$ as compared to just over $6 \mathrm{~cm}^{2} \mathrm{~V}^{-1} \mathrm{~s}^{-1}$ for the undoped OTFTs. Fig. 5c shows the statistical distribution of $\mu_{\mathrm{SAT}}$ measured from 80 pristine and 80 optimally p-doped $\left(0.75 \mathrm{~mol} \% \mathrm{C}_{60} \mathrm{~F}_{48}\right)$ OTFTs prepared by blade coating. Evidently, the average mobility for $\mathrm{p}$-doped devices remains significantly higher $\left(9.5 \mathrm{~cm}^{2} \mathrm{~V}^{-1} \mathrm{~s}^{-1}\right)$ than the values extracted for the pristine devices $\left(\approx 4.5 \mathrm{~cm}^{2} \mathrm{~V}^{-1} \mathrm{~s}^{-1}\right)$.

The large difference in hole mobility values between the pristine and p-doped blend OTFTs in Fig. 5c most likely indicates different transport mechanisms. Numerous high mobility organic semiconductors were shown to exhibit a characteristic increase in charge carrier mobility with reducing temperature (band-like behaviour) and was described by invoking a dynamic disorder model. ${ }^{59-61}$ Nevertheless, for the vast majority of these molecular systems, this transport regime occurs at relatively high temperatures and above a critical temperature $\left(T_{\mathrm{C}}\right)$. Below this characteristic temperature, thermal activation sets-in. The cross-over between the two transport regimes is typically understood in terms of charge carrier localization due to the presence of shallow traps, which tend to dominate charge transport at low temperatures. The origin of these trap states can differ for different materials and may relate to structural defects, grain-boundaries and on the presence of chemical impurities. ${ }^{62}$ If the extent of the disorder is reduced (i.e. reducing the trap density) the cross-over between band-like and thermally activated transport is shifted to lower temperatures and the activation energy $\left(E_{\mathrm{a}}\right)$ reduces. $^{63}$ In the case of the polycrystalline layers studied here, however, the grain boundaries present between crystalline domains are known to be the source of the structural disorder ${ }^{64}$ and it remains to be seen whether p-type doping plays a role. For single-crystalline $\mathrm{C}_{8}$-BTBT-based OTFTs where such grain boundaries are largely absent, band-like transport has indeed been observed. ${ }^{65}$

Fig. $5 \mathrm{~d}$ and e displays the $I_{\mathrm{DS}}^{1 / 2}$ vs. $V_{\mathrm{GS}}$ plots measured at different temperatures for pristine and p-doped blend OTFTs processed via blade-coating. Interestingly, both types of devices exhibit band-like transport for temperatures above $T_{\mathrm{C}}$. At $T<T_{\mathrm{C}}$, the hole mobility becomes thermally activated in both pristine and p-doped transistors, but with the two exhibiting different $E_{\mathrm{A}}$ values. Similar trends have been reported for various organic semiconductors and associated with the presence of structural disorder in the active layers. ${ }^{62,63,65}$ A noticeable difference between the two samples is seen both in terms of $T_{\mathrm{C}}$ and $E_{\mathrm{A}}$ values. In particular, pristine OTFTs show a $T_{\mathrm{C}}$ of $210 \mathrm{~K}$ while for the p-doped devices the $T_{\mathrm{C}}$ drops to $\approx 140 \mathrm{~K}$, with a simultaneous decrease of the $E_{\mathrm{A}}$ measured below $T_{\mathrm{C}}$. Specifically, pristine OTFTs exhibit an activation energy of $\approx 52.6 \mathrm{meV}$, while 


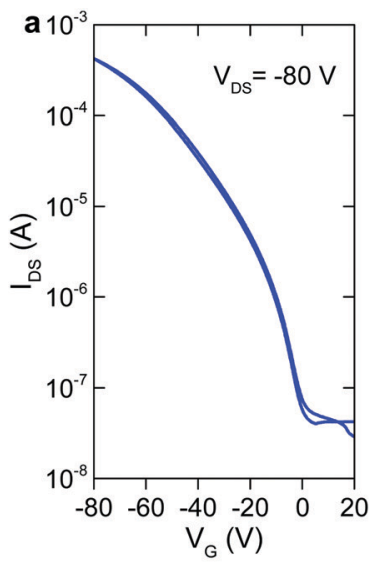

d

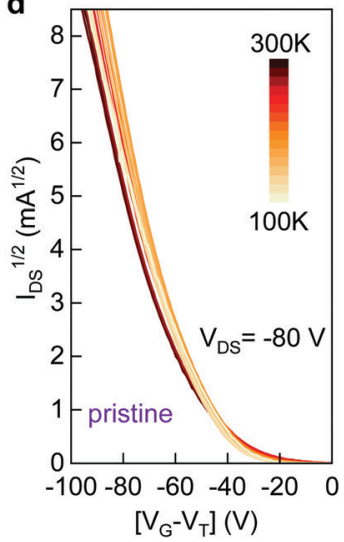

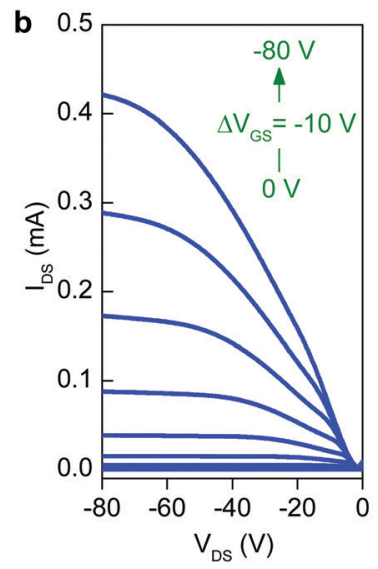

e

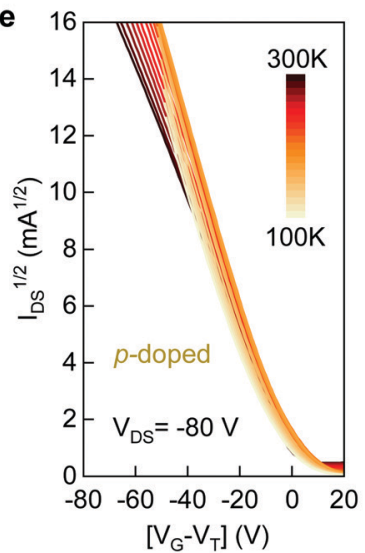

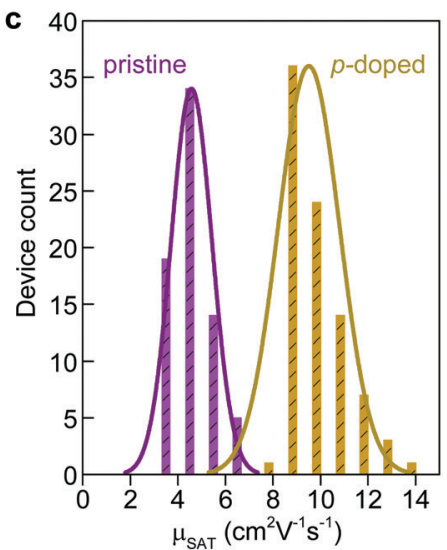

f

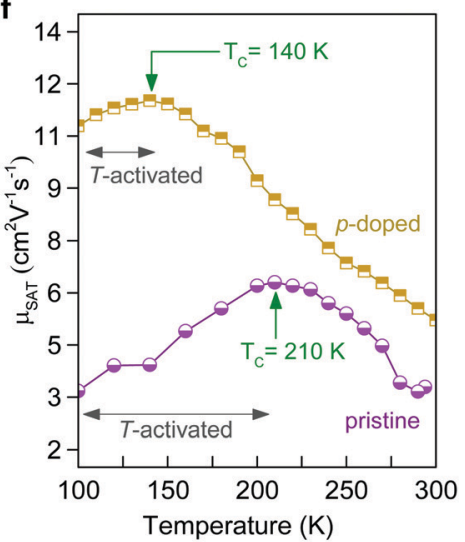

Fig. 5 (a) Transfer and (b) output characteristics of a representative $p$-doped $\mathrm{C}_{8}$-BTBT:C ${ }_{16}$ IDT-BT-based OTFT processed via blade-coating. (c) Histogram of the hole mobility measured in saturation ( $\mu_{\mathrm{SAT}}$ ) for pristine and p-doped blend OTFTs. (d and e) Plots of the square root of the channel current $\left(I_{D S}{ }^{0.5}\right)$ versus $V_{G S}$ measured at different temperatures in the range 100-300 $\mathrm{K}$ for pristine and p-doped OTFTs prepared by blade-coating. (f) Dependence of $\mu_{\mathrm{SAT}}$ on temperature for pristine and p-doped blend OTFTs calculated form the data in (d) and (e). The channel width and length for all devices studied were $1000 \mu \mathrm{m}$ and $80 \mu \mathrm{m}$, respectively.

$\mathrm{C}_{60} \mathrm{~F}_{48}$-doped transistors show a significantly reduced $E_{\mathrm{A}}$ of $\approx 29.4 \mathrm{meV}$. This observation, again, suggests that inclusion of $\mathrm{C}_{60} \mathrm{~F}_{48}$ at optimal concentrations in the blend leads to reduced energetic disorder and improved charge transport. These observations are in line with the microstructural analysis which shows that the combination of p-doping and blade-coating improves the structural quality of the resulting blend layers, ultimately resulting in the greatly improved hole-transport seen in Fig. $5 f$.

\section{Conclusions}

We have studied the influence of molecular p-doping on holetransport in small-molecule:polymer blend OTFTs processed via conventional spin-coating and the industry-relevant technique of blade-coating. OTFTs prepared by blade-coating are found to consistently outperformed those prepared via spincoating yielding a maximum hole mobility of $14 \mathrm{~cm}^{2} \mathrm{~V}^{-1} \mathrm{~s}^{-1}$. Irrespective of the deposition method, the blend layers exhibit a vertically phase-separated microstructure where the $\mathrm{C}_{8}$-BTBT segregates atop a $\mathrm{C}_{16}$ IDT-BT-dominant phase. Introducing the molecular dopant $\mathrm{C}_{60} \mathrm{~F}_{48}$ in the semiconducting blend was found to p-dope the formed layers, but also affects the crystallization kinetics of $\mathrm{C}_{8}$-BTBT phase leading to enhanced in-plane molecular packing of the $\mathrm{C}_{8}$-BTBT component, as corroborated by 2D GIWAXS and AFM measurements, ultimately resulting to a higher hole mobility. The work highlights the compatibility of high mobility organic semiconducting blends with high throughput printing techniques relevant to numerous emerging technologies.

\section{Experimental}

\subsection{Material preparation and device fabrication}

$\mathrm{C}_{8}$-BTBT was purchased from 1-Material and used as received. Molecular dopant $\mathrm{C}_{60} \mathrm{~F}_{48}$ was synthesized from $\mathrm{C}_{60}$ and molecular fluorine, $\mathrm{F}_{2}$, using a modified method described elsewhere ${ }^{66}$ Its purity of $98 \mathrm{~mol} \%$ was confirmed by ${ }^{19} \mathrm{~F}$ NMR, mass spectrometry and high performance liquid chromatography. The solution formulations were prepared using previously reported protocols. ${ }^{16}$ In brief, we used a weight ratio of $\mathrm{C}_{8}$-BTBT to $\mathrm{C}_{16}$ IDT-BT of $1: 3$ with a total solid content of $10 \mathrm{mg}$ per $\mathrm{ml}^{-1}$ of solvent. The solution was prepared in a chlorobenzene and tetralin $(1: 1) \mathrm{mix}$ solvent. The blend was doped with four different concentration of $\mathrm{C}_{60} \mathrm{~F}_{48}$ dopant 
$(0.1,0.75,2$ and $4.25 \mathrm{~mol} \%)$. OTFTs were fabricated with a top-gate, bottom-contact (TG-BC) architecture onto $2.54 \times$ $2.54 \mathrm{~cm}^{2}$ large glass substrates. The $\mathrm{Al} / \mathrm{Au}(5 / 35 \mathrm{~nm})$ source and drain electrodes were vapor deposited using shadow mask on the glass substrates and were further treated with the contact modifier Pentafluorothiophenol (PFBT) monolayer. The blend semiconducting layers were deposited using spin-coating and blade-coating. Previously reported experimental conditions were used for the spin-coated films. ${ }^{17}$ For blade-coating, the blend solutions were coated on the substrates at $70{ }^{\circ} \mathrm{C}$ with the blade speed of $50 \mathrm{~mm} \mathrm{~s}^{-1}$. The films where then subjected to an additional annealing step at $120{ }^{\circ} \mathrm{C}$ for $1 \mathrm{~min}$. A $\approx 900 \mathrm{~nm}$-thick CYTOP film was deposited on top of the blend semiconductor by spin-coating at $2000 \mathrm{rpm}$ followed by annealing at $50{ }^{\circ} \mathrm{C}$ for $1 \mathrm{~h}$ in nitrogen atmosphere. The geometrical capacitance of the CYTOP layers was measured to be $\approx 2.1 \mathrm{nF} \mathrm{cm}^{-2}$. Finally, a $70 \mathrm{~nm}$-thick Al layer was vapor deposited atop serving as the gate electrode. The digital photographs of spin-coated and blade-coated devices are shown in Fig. S8 (ESI $\dagger$ ) along with the device dimensions and source-drain (S-D) electrode distribution. Electrical transistor characterisation was performed using a Keysight B2912A Precision Source/Measure Unit.

\subsection{Field-effect charge carrier mobility calculations}

The field-effect charge carrier mobility was calculated from the transfer characteristics of the transistors in the saturation regime using.

$$
\mu_{\mathrm{SAT}}=\frac{L \vartheta^{2} I_{\mathrm{Dsat}}}{W C_{i} \vartheta V_{\mathrm{G}}^{2}}
$$

In eqn (1), $L$ and $W$ are the transistor channel length and width respectively, $V_{\mathrm{G}}$ is the applied gate voltage, $C_{\mathrm{i}}$ the geometrical capacitance of the gate dielectric employed, and $I_{\text {Dsat }}$ the channel current measured in saturation.

\subsection{Polarized optical microscopy}

Nikon LV-100 microscope was used to perform high speed POM and the images were recorded using a Photron SA-3 CMOS camera.

\subsection{Atomic force microscopy}

An Agilent 5500 instrument was used to perform all AFM measurements. The scanning speed was set at 0.2 lines $\mathrm{s}^{-1}$. The image processing and the statistical analysis of the images were done using Gwyddion software.

\subsection{Transmission electron microscopy}

A transmission electron microscope of model Titan $\mathrm{G}^{2}$ 80-300 ST from Thermo-Fisher Scientific was used to perform the cross-sectional TEM (X-TEM) analysis of the samples. The TEM instrument is equipped with a spherical aberration corrector for the condenser lens and an energy-filter GIF-Quantum 966 from Gatan Inc. for aberration corrected scanning TEM (AC-STEM) and electron energy loss spectroscopy (EELS), respectively. Further, the microscope was operated at the accelerating voltage of $300 \mathrm{kV}$ and in STEM mode during the analysis of the samples. The AC-STEM images were generated by collecting the transmitted electron beam with a retractable analogue high angular annular dark-field (HAADF) detector installed above the projection chamber of the microscope. The morphology and thickness of each layer in the stacks was investigated by acquiring the HAADF-STEM images at various magnifications. Whereas, the elemental maps of the main constituents namely, sulphur (S), carbon (C), and oxygen (O) were generated by acquiring the EELS datasets from the samples in a synchronized fashion during the STEM imaging. Furthermore, the elemental maps of $\mathrm{S}, \mathrm{C}$, and $\mathrm{O}$ were generated by acquiring their $\mathrm{S}-\mathrm{L}_{23}, \mathrm{C}-\mathrm{K}$, and $\mathrm{O}-\mathrm{K}$ energy-loss edges at the energy of $165 \mathrm{eV}, 283 \mathrm{eV}$, and $532 \mathrm{eV}$, respectively. In this way, the STEM-EELS data-cubes were acquired and processed to generate individual as well as RGB Composite elemental maps.

\subsection{Grazing-incidence wide-angle $X$-ray scattering}

Wide-angle X-ray scattering (GIWAXS) measurements were performed at the non-crystalline diffraction beamline (BL11-NCDSweet) at ALBA Synchrotron Radiation Facility in Barcelona (Spain). A Rayonix, WAXS LX255-HS detector was used to collect the scattering signals, resolution: $1920 \times 5760$ pixels (pixel size $=$ $40 \times 40 \mu \mathrm{m}^{2}$ ). Data are expressed as a function of the scattering vector $(q)$ and the angle of incidence was $0.1^{\circ}$. GIWAXS patterns were corrected as a function of the components of the scattering vector with a Matlab script designed for this purpose. ${ }^{67}$ Integrations have been done with Fit2D software.

\section{Conflicts of interest}

There are no conflicts to declare.

\section{Acknowledgements}

This publication is based upon work supported by the King Abdullah University of Science and Technology (KAUST) Office of Sponsored Research (OSR) under Award No: RPE/1/4196-01. The authors would like to thank ALBA synchrotron and staff for their help with the GIWAXS measurements.

\section{References}

1 H. Sun, Q. Wang, J. Qian, Y. Yin, Y. Shi and Y. Li, Semicond. Sci. Technol., 2015, 30, 054001.

2 S. D. Brotherton and S. D. Brotherton, Introduction to Thin Film Transistors, Springer International Publishing, 2013, pp. 185-251.

3 S. Wang, J. Xu, W. Wang, G. J. N. Wang, R. Rastak, F. MolinaLopez, J. W. Chung, S. Niu, V. R. Feig, J. Lopez, T. Lei, S. K. Kwon, Y. Kim, A. M. Foudeh, A. Ehrlich, A. Gasperini, Y. Yun, B. Murmann, J. B. H. Tok and Z. Bao, Nature, 2018, 555, 83-88.

4 Y. Yuan, G. Giri, A. L. Ayzner, A. P. Zoombelt, S. C. B. Mannsfeld, J. Chen, D. Nordlund, M. F. Toney, J. Huang and Z. Bao, Nat. Commun., 2014, 5, 3005. 
5 Y. Diao, B. C. K. Tee, G. Giri, J. Xu, D. H. Kim, H. A. Becerril, R. M. Stoltenberg, T. H. Lee, G. Xue, S. C. B. Mannsfeld and Z. Bao, Nat. Mater., 2013, 12, 665-671.

6 R. R. Søndergaard, M. Hösel and F. C. Krebs, J. Polym. Sci., Part B: Polym. Phys., 2013, 51, 16-34.

7 H. A. Becerril, M. E. Roberts, Z. Liu, J. Locklin and Z. Bao, Adv. Mater., 2008, 20, 2588-2594.

8 P. Yadav, C. Chanmal, A. Basu, L. Mandal, J. Jog and S. Ogale, RSC Adv., 2013, 3, 18049-18054.

9 B. Peng, X. Ren, Z. Wang, X. Wang, R. C. Roberts and P. K. L. Chan, Sci. Rep., 2014, 4, 6430.

10 H. Li, B. C. K. Tee, J. J. Cha, Y. Cui, J. W. Chung, S. Y. Lee and Z. Bao, J. Am. Chem. Soc., 2012, 134, 2760-2765.

11 Y. Lee, J. Y. Oh, T. R. Kim, X. Gu, Y. Kim, G. J. N. Wang, H. C. Wu, R. Pfattner, J. W. F. To, T. Katsumata, D. Son, J. Kang, J. R. Matthews, W. Niu, M. He, R. Sinclair, Y. Cui, J. B. H. Tok, T. W. Lee and Z. Bao, Adv. Mater., 2018, 30(7), 1704401.

12 R. H. Kim, H. J. Kim, I. Bae, S. K. Hwang, D. B. Velusamy, S. M. Cho, K. Takaishi, T. Muto, D. Hashizume, M. Uchiyama, P. André, F. Mathevet, B. Heinrich, T. Aoyama, D. E. Kim, H. Lee, J. C. Ribierre and C. Park, Nat. Commun., 2014, 5, 3583.

13 G. Gelinck, P. Heremans, K. Nomoto and T. D. Anthopoulos, Adv. Mater., 2010, 22, 3778-3798.

14 H. Matsui, Y. Takeda and S. Tokito, Org. Electron., 2019, 75, 105432.

15 E. Menard, V. Podzorov, S. H. Hur, A. Gaur, M. E. Gershenson and J. A. Rogers, Adv. Mater., 2004, 16, 2097-2101.

16 A. F. Paterson, N. D. Treat, W. Zhang, Z. Fei, G. Wyatt-Moon, H. Faber, G. Vourlias, P. A. Patsalas, O. Solomeshch, N. Tessler, M. Heeney and T. D. Anthopoulos, Adv. Mater., 2016, 28, 7791-7798.

17 A. F. Paterson, L. Tsetseris, R. Li, A. Basu, H. Faber, A. Emwas, J. Panidi, Z. Fei, M. R. Niazi, D. H. Anjum, M. Heeney and T. D. Anthopoulos, Adv. Mater., 2019, 31, 1900871.

18 A. F. Paterson, S. Singh, K. J. Fallon, T. Hodsden, Y. Han, B. C. Schroeder, H. Bronstein, M. Heeney, I. McCulloch and T. D. Anthopoulos, Adv. Mater., 2018, 30.

19 W. Pisula, A. Menon, M. Stepputat, I. Lieberwirth, U. Kolb, A. Tracz, H. Sirringhaus, T. Pakula and K. Müllen, Adv. Mater., 2005, 17, 684-688.

20 R. L. Headrick, S. Wo, F. Sansoz and J. E. Anthony, Appl. Phys. Lett., 2008, 92, 063302.

21 C. M. Duffy, J. W. Andreasen, D. W. Breiby, M. M. Nielsen, M. Ando, T. Minakata and H. Sirringhaus, Chem. Mater., 2008, 20, 7252-7259.

22 D. Khim, H. Han, K. J. Baeg, J. Kim, S. W. Kwak, D. Y. Kim and Y. Y. Noh, Adv. Mater., 2013, 25, 4302-4308.

23 M. R. Niazi, R. Li, E. Qiang Li, A. R. Kirmani, M. Abdelsamie, Q. Wang, W. Pan, M. M. Payne, J. E. Anthony, D. M. Smilgies, S. T. Thoroddsen, E. P. Giannelis and A. Amassian, Nat. Commun., 2015, 6, 8598.

24 K. Kim, J. Hong, S. G. Hahm, Y. Rho, T. K. An, S. H. Kim and C. E. Park, ACS Appl. Mater. Interfaces, 2019, 11, 13481-13490.

25 R. L. Davis, S. Jayaraman, P. M. Chaikin and R. A. Register, Langmuir, 2014, 30, 5637-5644.
26 M. Richard, A. Al-Ajaji, S. Ren, A. Foti, J. Tran, M. Frigoli, B. Gusarov, Y. Bonnassieux, E. G. Caurel, P. Bulkin, R. Ossikovski and A. Yassar, Adv. Colloid Interface Sci., 2020, 275.

27 M. Chen, B. Peng, S. Huang and P. K. L. Chan, Adv. Funct. Mater., 2020, 30, 1905963.

28 K. Haase, C. Teixeira da Rocha, C. Hauenstein, Y. Zheng, M. Hambsch and S. C. B. Mannsfeld, Adv. Electron. Mater., 2018, 4, 1-9.

29 S. Arai, S. Inoue, T. Hamai, R. Kumai and T. Hasegawa, Adv. Mater., 2018, 30, 1707256.

30 G. Giri, E. Verploegen, S. C. B. Mannsfeld, S. Atahan-Evrenk, D. H. Kim, S. Y. Lee, H. A. Becerril, A. Aspuru-Guzik, M. F. Toney and Z. Bao, Nature, 2011, 480, 504-508.

31 F. G. Del Pozo, S. Fabiano, R. Pfattner, S. Georgakopoulos, S. Galindo, X. Liu, S. Braun, M. Fahlman, J. Veciana, C. Rovira, X. Crispin, M. Berggren and M. Mas-Torrent, Adv. Funct. Mater., 2016, 26, 2379-2386.

32 Z. Zhang, B. Peng, X. Ji, K. Pei and P. K. L. Chan, Adv. Funct. Mater., 2017, 27, 1703443.

33 A. Yamamura, S. Watanabe, M. Uno, M. Mitani, C. Mitsui, J. Tsurumi, N. Isahaya, Y. Kanaoka, T. Okamoto and J. Takeya, Sci. Adv., 2018, 4, eaao5758.

34 B. Peng, S. Huang, Z. Zhou and P. K. L. Chan, Adv. Funct. Mater., 2017, 27, 1700999.

35 Y. Abe, T. Hasegawa, Y. Takahashi, T. Yamada and Y. Tokura, Appl. Phys. Lett., 2005, 87, 1-3.

36 K. Zhao, O. Wodo, D. Ren, H. U. Khan, M. R. Niazi, H. Hu, M. Abdelsamie, R. Li, E. Q. Li, L. Yu, B. Yan, M. M. Payne, J. Smith, J. E. Anthony, T. D. Anthopoulos, S. T. Thoroddsen, B. Ganapathysubramanian and A. Amassian, Adv. Funct. Mater., 2016, 26, 1737-1746.

37 C. Teixeira da Rocha, K. Haase, Y. Zheng, M. Löffler, M. Hambsch and S. C. B. Mannsfeld, Adv. Electron. Mater., 2018, 4(8), 1800141.

38 G. Zhang, H. Yang, L. He, L. Hu, S. Lan, F. Li, H. Chen and T. Guo, J. Polym. Sci., Part B: Polym. Phys., 2016, 54, 1760-1766. 39 J. Smith, R. Hamilton, I. McCulloch, N. Stingelin-Stutzmann, M. Heeney, D. D. C. Bradley and T. D. Anthopoulos, J. Mater. Chem., 2010, 20, 2562-2574.

40 A. D. Scaccabarozzi and N. Stingelin, J. Mater. Chem. A, 2014, 2, 10818-10824.

41 S. Scheinert, G. Paasch, S. Pohlmann, H. H. Hörhold and R. Stockmann, Solid-State Electron., 2000, 44, 845-853.

42 J. H. Oh, P. Wei and Z. Bao, Appl. Phys. Lett., 2010, 97, 243305.

43 L. Ma, W. H. Lee, Y. D. Park, J. S. Kim, H. S. Lee and K. Cho, Appl. Phys. Lett., 2008, 92, 063310.

44 C. T. Lee and H. C. Chen, Org. Electron., 2011, 12, 1852-1857.

45 E. Lim, B. J. Jung, M. Chikamatsu, R. Azumi, Y. Yoshida, K. Yase, L. M. Do and H. K. Shim, J. Mater. Chem., 2007, 17, 1416-1420. 46 S. Riera-Galindo, F. Leonardi, R. Pfattner and M. MasTorrent, Adv. Mater. Technol., 2019, 4, 1900104.

47 R. Hamilton, J. Smith, S. Ogier, M. Heeney, J. E. Anthony, I. McCulloch, J. Veres, D. D. C. Bradley and T. D. Anthopoulos, Adv. Mater., 2009, 21, 1166-1171. 
48 J. Smith, W. Zhang, R. Sougrat, K. Zhao, R. Li, D. Cha, A. Amassian, M. Heeney, I. McCulloch and T. D. Anthopoulos, Adv. Mater., 2012, 24, 2441-2446.

49 X. Gu, L. Shaw, K. Gu, M. F. Toney and Z. Bao, Nat. Commun., 2018, 9.

50 M. Le Berre, Y. Chen and D. Baigl, Langmuir, 2009, 25, 2554-2557.

51 Y. Diao, L. Shaw, Z. Bao and S. C. B. Mannsfeld, Energy Environ. Sci., 2014, 7, 2145-2159.

52 K. Zhao, O. Wodo, D. Ren, H. U. Khan, M. R. Niazi, H. Hu, M. Abdelsamie, R. Li, E. Q. Li, L. Yu, B. Yan, M. M. Payne, J. Smith, J. E. Anthony, T. D. Anthopoulos, S. T. Thoroddsen, B. Ganapathysubramanian and A. Amassian, Adv. Funct. Mater., 2016, 26, 1737-1746.

53 A. F. Paterson, Y.-H. Lin, A. D. Mottram, Z. Fei, M. R. Niazi, A. R. Kirmani, A. Amassian, O. Solomeshch, N. Tessler, M. Heeney and T. D. Anthopoulos, Adv. Electron. Mater., 2018, 4, 1700464.

54 H. I. Un, J. Y. Wang and J. Pei, Adv. Sci., 2019, 6, 1900375. 55 H. Sirringhaus, Adv. Mater., 2005, 17, 2411-2425.

56 S. Zafar, A. Callegari, E. Gusev and M. V. Fischetti, J. Appl. Phys., 2003, 93, 9298.

57 I. Amit, T. J. Octon, N. J. Townsend, F. Reale, C. D. Wright, C. Mattevi, M. F. Craciun and S. Russo, Adv. Mater., 2017, 29, 1605598.
58 A. F. Paterson, Y. H. Lin, A. D. Mottram, Z. Fei, M. R. Niazi, A. R. Kirmani, A. Amassian, O. Solomeshch, N. Tessler, M. Heeney and T. D. Anthopoulos, Adv. Electron. Mater., 2017, 4(10), 1700464.

59 S. Ciuchi, S. Fratini and D. Mayou, Phys. Rev. B: Condens. Matter Mater. Phys., 2015, 83(8), 081202.

60 Y. C. Cheng and R. J. Silbey, J. Chem. Phys., 2003, 118, 3764-3774.

61 J. D. Picon, M. N. Bussac and L. Zuppiroli, Phys. Rev. B: Condens. Matter Mater. Phys., 2007, 75(23), 235106.

62 H. Sirringhaus, T. Sakanoue and J. F. Chang, Phys. Status Solidi B, 2012, 249, 1655-1676.

63 N. A. Minder, S. Lu, S. Fratini, S. Ciuchi, A. Facchetti and A. F. Morpurgo, Adv. Mater., 2014, 26, 1254-1260.

64 J. Smith, R. Hamilton, I. McCulloch, N. Stingelin-Stutzmann, M. Heeney, D. D. C. Bradley and T. D. Anthopoulos, J. Mater. Chem., 2010, 20, 2562-2574.

65 J. M. Cho, T. Higashino and T. Mori, Appl. Phys. Lett., 2015, 106, 1-5.

66 O. V. Boltalina and N. A. Galeva, Usp. Khim., 2000, 69, 673-674. 67 A. Nogales and E. Gutiérrez, 2D Representation of a Wide Angle $\mathrm{X}$ Ray Scattering pattern as a function of $Q$ vector components, https://jp.mathworks.com/matlabcentral/fileexchange/ 71958-grazing-incidence-wide-angle-x-ray-scatteringrepresentation, accessed 10 March 2020. 